Cite as: Fidel-Kinori, S. G., Eiroa-Orosa, F. J., Giannoni-Pastor, A., Tasqué-Cebrián, R., Arguello, J. M., \& Casas, M. (2016). The Fenix II study: A longitudinal study of psychopathology among burn patients. Burns, 42(6), 1201-1211. http://doi.org/10.1016/j.burns.2016.01.026

\title{
The Fenix II Study: A longitudinal study of psychopathology among burn patients
}

Fidel-Kinori, Sara Guila ${ }^{*} ;$ Eiroa-Orosa, Francisco Jose ${ }^{2 *}$; Giannoni-Pastor, Anna ${ }^{1 *}$; Tasqué-Cebrián, Ruth ${ }^{1}$; Arguello, Jose Maria' ${ }^{\text {; Casas, Miguel }}{ }^{1}$

1. Department of Psychiatry. University Hospital Vall d'Hebron. CIBERSAM. Universitat Autònoma de Barcelona, Catalonia, Spain.

2. School of Psychology, University of East London.

* The first three authors contributed equally to this work, and all authors contributed to the development of the project in its different stages.

Address of correspondence

Dr Francisco Jose Eiroa Orosa

Secció de Personalitat, Avaluació i Tractament Psicològic

Departament de Psicologia Clínica i Psicobiologia

Institut de Neurociències

Facultat de Psicologia

Universitat de Barcelona

Passeig Vall d'Hebron, 171

08035 Barcelona

fjeiroa@gmail.com 


\title{
The Fenix II Study: A longitudinal study of psychopathology among burn patients
}

\begin{abstract}
Psychological symptoms are common among burn survivors. However, knowledge about epidemiology and predictors of psychopathology has shown great heterogeneity in this population. The Fenix-II Project was the first epidemiological study on the psychopathological consequences of burn injuries developed in Spain, providing a detailed analysis of the progression of psychological symptoms during the first six months after injury. Three hundred and thirty-three patients were monitored and 183 were included in this study. Posttraumatic, depression and anxiety symptoms showed a general decreasing tendency across time. At 6 months, 34 patients showed clinically significant Posttraumatic Stress Disorder (PTSD) symptoms (20.5\% of 166 patients reached at 6 months) as measured with the MINI Neuropsychiatric Interview. Within this group of patients, anxiety, depression and hyperarousal increased at 30 days, and avoidance 90 days after injury. The most accurate predictors of PTSD were found to be being burned in a Motor Vehicle Accident, risk of social exclusion, low body-image adjustment, anterior trunk location of the burn injury and life threat perception during the burn-shock period. Considering these factors, clinicians may identify patients at risk of PTSD development, allowing an adequate follow up and preventive interventions which may minimize the psychological consequences of burn injuries.
\end{abstract}

Key words: Burn patients; psychopathology; epidemiology; Acute Stress; PTSD 


\section{Introduction}

The incidence of burn injuries requiring medical care is nearly 11 million people a year throughout the World [1], producing significant morbidity, long-term disabilities and still in many cases, fatalities. Advances in the prevention and approaches to fire extinguishment have reduced the extension of, and mortality caused by burn injuries [2]. Furthermore, while about 60 years ago the survival rates of patients with a total burn surface area (TBSA) covering $40 \%$ of the body was $50 \%$, currently people with a $70 \%$ TBSA have the same survival rates [3]. This increase in survival due to the improvement of medical treatments has enabled a specific focus on the mental health of burn survivors [4]. Within these new approaches, psychosocial assessment and interventions have made significant progress in the prevention, detection and treatment of the mental health consequences following a burn injury [5].

Psychological sequels of burn injuries involve mainly affective and anxiety symptomatology [6]. Although diagnoses such as major depression and generalized anxiety are common in these patients [7-9], the emergence of acute and posttraumatic stress disorders (ASD and PTSD respectively) as specific diagnoses allowed a more detailed analysis of the acute psychological consequences of burn injuries and its risk of chronification [10,11]. However, literature in this field is still scarce.

Regarding its epidemiology, prevalence rates of PTSD in burn patients range from 3\% to $45 \%$ [12]. In this regard, epidemiological studies on the progression of PTSD symptoms within burned patients have mainly been conducted in the U.S. and Nordic European countries where treatment is highly developed. However, there have been some studies coming from Mediterranean [13] and some emergent countries [14,15]; showing similar PTSD figures [12]. No major epidemiological differences should be expected from similarly developed areas, as the factors related to the incidence of PTSD are associated with the 
development of medical treatment at the time of the study, the type of population and the methodology with which the study was carried. However, as specific differences could be found in diverse clinical settings, we consider important to monitor the occurrence of psychological symptoms, adding methodological developments to improve the understanding of the risk factors for its development and progression.

Regarding the possible predictors of PTSD occurrence among burn survivors, clinical variables such as the occurrence of a blast, the amount of TBSA affected, previous affective disorders, delirium, dissociative experiences, severe pain during acute treatment, and the length of stay (LOS) in medical settings, appear as good predictors of psychological distress, including PTSD [10,16,17]. However, personal and subjective variables such as age, female gender, life threat perception during the burn-shock period, and lower levels of perceived social support, also appear to affect the course of psychological adjustment after a burn injury $[6,12,18-20]$. Indeed, according to some authors, subjective and personal variables may have a more pronounced impact on distress than the clinical characteristics of the burn injury $[13,21]$. Nevertheless, until now, few studies have systematically included a sufficient set of clinical and subjective factors, neither meta-analytic evidence seems enough to effectively predict the occurrence and chronification of PTSD symptomatology, and therefore, which patients have a greater need to receive preventive interventions.

The aim of this work was to explore the progression of psychological sequels among patients included in the Fenix-II, a longitudinal study of psychopathology in burn patients admitted to a specialized unit in Barcelona, Spain. This paper will focus on: (1) the epidemiology and progression of posttraumatic symptomatology across the first 6 months after burn injury, and (2) the clinical and psychosocial predictors of PTSD during this period of time. 


\section{Method}

\section{Participants.}

The Burn Centre of the Vall d'Hebron hospital system provides services for a total population of 8 million persons corresponding mainly to the Catalonia Region (an autonomous community with a total population of 7.5 million). The incidence of burns in Catalonia corresponds to the average in developed countries [22], with 31.2 per 100000 person/year referred to specialized units [23]. Four hundred and eighty nine patients were admitted into the Plastic Surgery and Burns Department of the Vall d'Hebron University Hospital in Barcelona (Spain) between April 2009 and June 2011 (see admission criteria in figure 1).

From this initial pool, three hundred and eighty three patients between 18 and 75 years of age were monitored, and 183 agreed to be included in the study after applying the following exclusion criteria: a) not enough Spanish/Catalan language proficiency; b) MiniMental State Examination <23; c) exitus and, d) recruitment limitations (i.e. short term admissions of less than 72 hours or admissions for follow up of long-term sequels). No patient explicitly withdrawn consent once included in the study. A flow chart of the study can be seen in figure 1. 
Figure 1. Flow diagram of the study

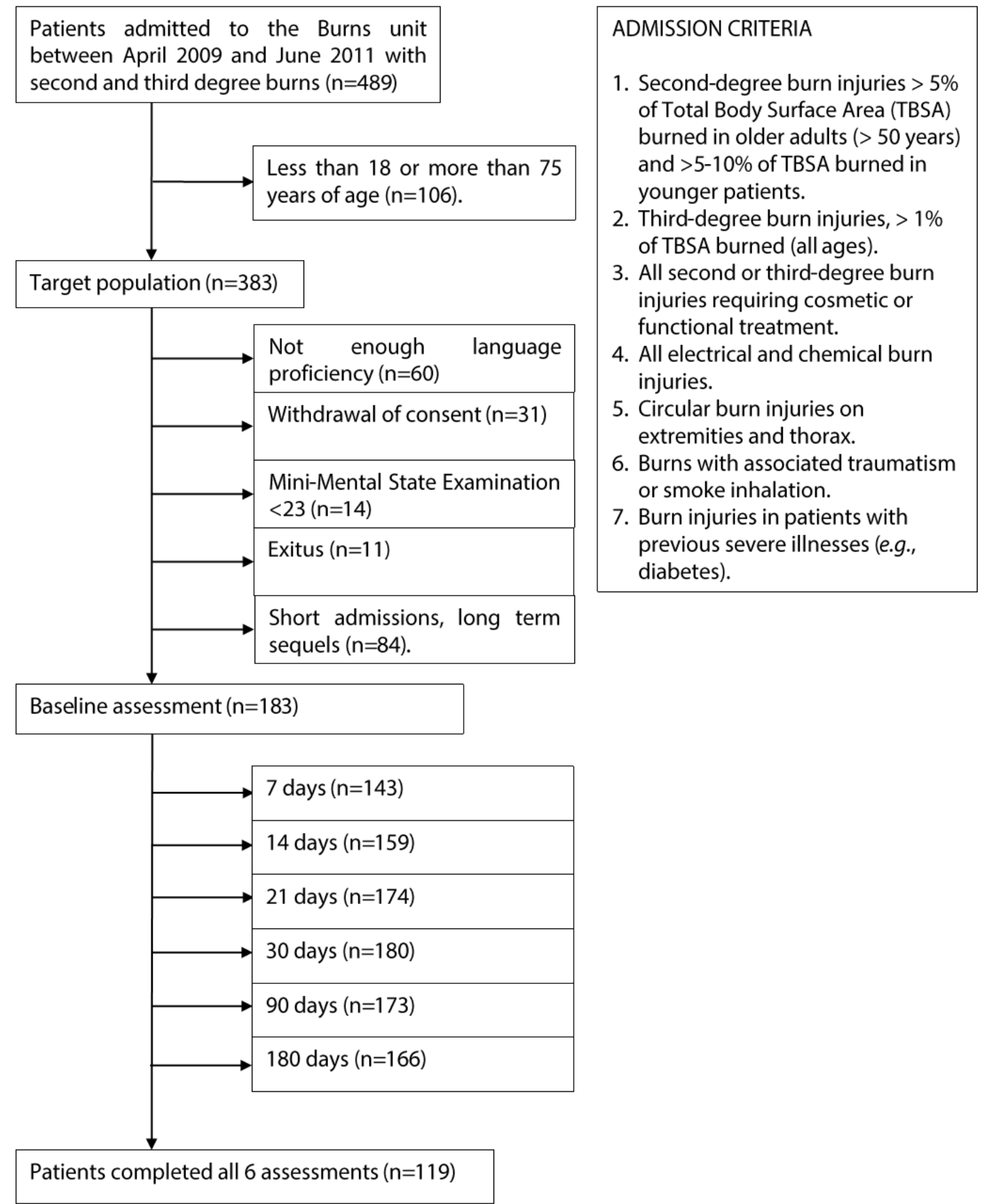

Study design and procedure.

This study was a longitudinal follow-up across 6 months, in which 6 assessments were made, at 7, 14, 21, 30, 90 and 180 days after the burn injury. An ad-hoc structured baseline 
interview which included sociodemographic and relevant medical history data as well as characteristics of the burn injury was administered by two trained psychologists. Additionally, a battery of self-administered questionnaires was provided to participants in each assessment (please see instruments section below). The study was approved by the Clinical Research Ethics Committee of the hospital. Additionally, patients included in this study accepted participation in a voluntary and anonymous basis by signing an informed consent according to the Helsinki Declaration (amended in Tokyo, 2004).

\section{Measures.}

As said above, an ad-hoc inventory was used to record the sociodemographic characteristics including age, gender, marital status, cohabitation, education, employment, access to housing and perceived social support (support from family, colleagues, and friends measured with a 1-5 Likert scale). Injury and clinical features included TBSA, LOS, degree of burn injury, body location, etiology, place of occurrence (including home, work, street, camping/ barbecue, vehicle, and a small amount of other settings such as public buildings), circumstance of occurrence (including occupational, suicide attempt, motor vehicle accident, aggression and other accidents, i.e. accidents in which none of the previous circumstances were applicable, mostly daily activities which are supposed to imply low risk such as scald or steam burns), presence of other affected people, body-image adjustment (measured with the question: Do you see any changes in your body image? If yes, how do you experience them? And taking "yes" and "badly" as low adjustment), peritraumatic conditions (based on the CAPS [24] dissociation section, i.e. a 1-5 Likert frequency scale asking for the presence of dissociative amnesia, derealization, sensory numbness, depersonalization and emotional numbness; and dichotomic questions asking for the occurrence of emotional paralysis, loss of awareness and life threat perception, previous mental health problems and substance use. 
In order to clarify if there was any cognitive impairment condition likely to invalidate any response (e.g., dementia, traumatic brain injury or impairments due to smoke inhalation), patients were assessed using the Mini-Mental Estate Examination [25]. The rest of psychometric instruments included the following list.

a) Anxiety was measured using the State Trait Anxiety Inventory, STAI [26], a commonly used inventory of trait and state anxiety consisting of 40 questions on a self-report basis. This questionnaire allows the differentiation of anxiety derived from personality traits, with anxiety related to the fluctuation of patients' recovery.

b) Depression was assessed using the 1996 version of Beck Depression Inventory, BDIII [27]. This 21-question self-report inventory is probably the most widely used psychometric test for measuring the severity of depression, thus allowing comparability with other studies made on burn injuries or other medical conditions.

c) The 1997 revision of the Impact of Events Scale, IES-R [28] was selected to measure the three-clustered stress response to trauma because of its psychometric properties and consequent three factor structure specifically validated within burn survivors [29].

d) The Davidson Trauma Scale, DTS [30], was used to measure posttraumatic symptoms severity and frequency only at 30,90 and 180 days assessments. Previous studies in burn patients have used this scale as a measure of posttraumatic symptomatology [31]. A DTS cut-off score of 40 was recommended by original authors, as the optimal cut-point for accurate classification of PTSD, but the values that demonstrated comparable efficiency were present across a range of different scores [32].

e) The MINI international neuropsychiatric interview [33], was used at six months to perform a clinical diagnosis of PTSD following DSM IV criteria. In the same way that other similar but more comprehensive instruments, such as the Structured Clinical Interview for DSM and the Composite International Diagnostic Interview, it has 
largely demonstrated its validity and reliability [34], and it has already been successfully used to assess PTSD in burn research [35].

All instruments used in this study have demonstrated to be valid and reliable, specifically among burn patients [36]. Although basic clinical information was collected on an ongoing basis for all participants, patients were given psychometric instruments whenever the medical team allowed it, depending on their level of consciousness and pain. We considered the criteria used in a previous study of burn patients [37], where the authors considered a minimum period of 72 hours after extubation due to reestablishment of comprehension and coherence. This meant that some patients could not be included at baseline or in the following assessments but were included as soon as it was possible. A flow chart specifying the number and characteristics of patients included in the study can be seen figure one.

\section{Statistical analyses.}

Descriptive analyses were executed for all sociodemographic and clinical features at every assessment. In order to verify if subjects included $(n=183)$ and excluded $(n=200)$ were statistically comparable, mean (for age and TBSA) and proportion comparisons (for gender) were carried out. The internal reliability of all instruments was checked using Cronbach's alphas at every assessment. A receiver operating characteristic (ROC) curve was used to determine the best threshold point for the DTS versus a PTSD diagnosis made following DSM criteria (MINI interview). Box Plots (complemented with skewness values) and Time Series graphs were used to represent the progression of symptomatology. The progression of symptoms among patients eventually diagnosed with PTSD and those without, besides those of which could not be located at 6 months (whose measures were calculated using multiple imputations), was compared using repeated measures mixed ANOVAs. Additionally, T and Chi Squared tests were performed in order to compare sociodemographic and clinical variables between subjects with or without PTSD at 6 months. In order to simplify the 
understanding and comparison of some sociodemographic characteristics, we dichotomized the following variables: marital status ( $\%$ in a relation), education ( $\%$ at least high school), employment (\% active) and economic income (\% in risk of social exclusion, according to the criterion of social exclusion of the Spanish ministry of labor and social affairs, establishing the concept as a continuous disadvantage in access to housing, education and employment). A standardized canonical discriminant analysis was carried with all variables that resulted in a statistically significant difference between patients with and without PTSD at 6 months, in order to weight each variable's influence on the occurrence of PTSD. This technique was chosen as the standardized canonical discriminant function coefficients offer a clear picture of the weight of each predictor. All analyses were two tailed at the $95 \%$ confidence interval level, and were performed using the SPSS 20.0 statistical package.

\section{Results}

\section{Differences between included and excluded patients}

No statistically significant differences were detected regarding gender, age or TBSA between patients included or not included in the study. Nevertheless, Levene's tests for equality of variances detected a statistically significant difference in variances both regarding age $(F=4.115, p=.043)$ and TBSA $(F=6.697, p<.01)$, reflecting greater heterogeneity in the group of excluded patients. A total of $33.3 \%$ of included patients and a $30.9 \%(O R=1.121$, 95\% $C I=725-1.733, p=.609$ ) of excluded patients had a large burn injury (equal or greater than $15 \%$ ). However, $39.4 \%$ of the excluded patients while $24 \%$ of the included, had less than 5\% TBSA $(O R=2.051,95 \% C I=1.310-3.209, p=.002)$.

\section{Sociodemographic and clinical characteristics of the sample}

Sociodemographic and clinical characteristics of the total included sample can be seen in table 1 and table 2 respectively. Participants' mean age was $41.14(S D=14.13), 29 \%$ were 
females, $68.3 \%$ were in a relation, $55.7 \%$ had at least secondary studies and the same percentage were considered to be professionally active. However, $23 \%$ of the sample reported continued difficulties accessing housing, education and/or employment (low income). Their mean TBSA burned was $14.1 \%(S D=13.97)$ and the average of LOS was 20.96 days $(S D=$ 20.36). From the sample, $31.1 \%$ suffered third-degree burns and $32.2 \%$ got injured in the presence of other people. Most burns were caused by flame $(61.7 \%)$ followed by scalds $(18.5 \%)$

Table 1. Sociodemographic features from included participants $(n=183)$, patients with PTSD and without at 6 months $(\mathrm{n}=166)$.

\begin{tabular}{|c|c|c|c|c|c|c|c|c|}
\hline \multirow[t]{2}{*}{ SOCIODEMOGRAPHICS } & \multicolumn{2}{|c|}{ NO PTSD $(n=132)$} & \multicolumn{2}{|c|}{ PTSD $(n=34)$} & \multirow[b]{2}{*}{$t$} & \multirow[b]{2}{*}{ Sig } & \multicolumn{2}{|c|}{ Included sample (n } \\
\hline & $M$ & $S D$ & $M$ & $S D$ & & & $M$ & $S D$ \\
\hline Age & 42.0 & 14.7 & 39.6 & 10.7 & 1.061 & .293 & 41.14 & 14.13 \\
\hline Social support (range 1-5) & & & & & & & & \\
\hline Family support & 4.5 & 0.9 & 4.4 & 1.1 & 0.809 & .422 & 4.4 & 0.9 \\
\hline Work support & 2.9 & 1.7 & 2.5 & 1.7 & 1.261 & .209 & 2.6 & 1.7 \\
\hline Friends support & 4.1 & 1.3 & 4 & 1.2 & 0.163 & .871 & 4 & 1.3 \\
\hline & $N$ & $\%$ & $N$ & $\%$ & $O R, 95 \%$ & Sig. & $N$ & $\%$ \\
\hline Gender (\% Females) & 36 & 27.3 & 13 & 38.2 & $1.65, .74-$ & .211 & 53 & 29 \\
\hline $\begin{array}{l}\text { Marital status } \\
\text { (\% not in a relation) }\end{array}$ & 9 & 29.5 & 39 & 26.5 & $.86, .36-$ & .724 & 58 & 31.7 \\
\hline Married & 65 & 49.2 & 17 & 50 & & & 86 & 47 \\
\hline In a relation & 28 & 21.2 & 8 & 23.5 & & & 39 & 21.3 \\
\hline Single & 19 & 14.4 & 4 & 11.8 & & & 28 & 15.3 \\
\hline Widow & 1 & 0.8 & 2 & 5.9 & & & 3 & 1.6 \\
\hline Divorced/separated & 19 & 14.4 & 3 & 8.8 & & & 27 & 14.7 \\
\hline Cohabitation (OR, alone vs. & & & & & $.78, .27-$ & .634 & & \\
\hline Alone & 24 & 18.2 & 5 & 14.7 & & & 34 & 18.6 \\
\hline With parents & 17 & 12.9 & 6 & 17.6 & & & 27 & 14.8 \\
\hline Own family & 91 & 68.9 & 23 & 67.6 & & & 122 & 66.7 \\
\hline Education (\% at least & 75 & 56.8 & 20 & 58.8 & $1.09, .51-$ & .833 & 102 & 55.7 \\
\hline University & 31 & 23.5 & 5 & 14.7 & & & 39 & 21.3 \\
\hline Secondary & 44 & 33.3 & 15 & 44.1 & & . & 63 & 34.4 \\
\hline Primary & 45 & 34.1 & 12 & 35.3 & & & 63 & 34.4 \\
\hline Illiterate & 12 & 9.1 & 2 & 5.9 & & & 16 & 8.7 \\
\hline Employment (\% active) & 83 & 62.9 & 16 & 47.1 & 1.91, .89- & .094 & 102 & 55.7 \\
\hline Employed & 73 & 55.3 & 13 & 38.3 & & & 89 & 48.6 \\
\hline Studying & 3 & 2.3 & 1 & 2.9 & & & 4 & 2.2 \\
\hline Studying and & 3 & 2.3 & 0 & 0 & & & 3 & 1.6 \\
\hline Domestic duties & 4 & 3 & 2 & 5.9 & & & 6 & 3.3 \\
\hline Retirement/ & 28 & 21.2 & 2 & 5.9 & & & 30 & 16.4 \\
\hline Unemployed & 21 & 15.9 & 16 & 47 & & & 50 & 27.4 \\
\hline Low economic income & 21 & 15.9 & 12 & 35.3 & $2.88,1.24-$ & .012 & 42 & 23 \\
\hline
\end{tabular}

Table 2. Injury and clinical features of the entire included sample $(n=183)$ and participants with PTSD and without it at 6 months $(n=166)$. 


\begin{tabular}{|c|c|c|c|c|c|c|c|c|}
\hline \multirow[t]{2}{*}{ INJURY FEATURES } & \multicolumn{2}{|c|}{$\begin{array}{l}\text { NO PTSD } \\
(\mathbf{n}=132)\end{array}$} & \multicolumn{3}{|c|}{$\begin{array}{l}\text { PTSD } \\
(n=34)\end{array}$} & \multicolumn{3}{|c|}{$\begin{array}{l}\text { TOTAL } \\
(\mathbf{n}=\mathbf{1 8 3})\end{array}$} \\
\hline & $\mathbf{M}$ & SD & $\mathbf{M}$ & SD & $\mathbf{t}$ & Sig. & $\mathbf{M}$ & SD \\
\hline TBSA & 12.4 & 11.1 & 18.7 & 20.4 & -1.73 & .091 & 14.05 & 13.97 \\
\hline LOS & 18.4 & 13.5 & 29.4 & 35.5 & -1.77 & .085 & 20.96 & 20.36 \\
\hline \multicolumn{9}{|c|}{ Peritraumatic conditions (range 1-5) } \\
\hline Dissociative amnesia & 1.4 & 1.0 & 2.1 & 1.5 & -2.47 & .018 & 1.6 & 1.3 \\
\hline Derealization & 1.2 & 0.6 & 1.6 & 1.0 & 1.89 & .066 & 1.3 & 0.7 \\
\hline Sensory numbness & 1.2 & 0.5 & 1.5 & 0.8 & -1.97 & .055 & 1.3 & 0.7 \\
\hline Depersonalization & 1.02 & 0.2 & 1.1 & 0.4 & .967 & .340 & 1.03 & 0.3 \\
\hline \multirow[t]{2}{*}{ Emotional numbness } & 1.1 & 0.6 & 1.3 & 0.9 & -1.26 & .215 & 1.2 & 0.7 \\
\hline & $\mathbf{N}$ & $\%$ & $\mathbf{N}$ & $\%$ & OR, 95\% CI & Sig. & $\mathbf{N}$ & $\%$ \\
\hline Emotional paralysis & 18 & 13.6 & 10 & 29.4 & $2.64,1.08-6.42$ & .028 & 35 & 19.1 \\
\hline Loss of awareness & 12 & 9.1 & 4 & 11.8 & $1.33, .40-4.43$ & .744 & 19 & 10.4 \\
\hline Life threat perception & 48 & 36.4 & 22 & 64.7 & $3.21,1.46-7.04$ & .003 & 79 & 43.2 \\
\hline Third-degree burns & 35 & 26.5 & 15 & 44.1 & $2.19,1.03-4.76$ & .046 & 57 & 31.1 \\
\hline Other injured people & 46 & 34.8 & 11 & 32.3 & $1.12, .50-2.50$ & .785 & 59 & 32.2 \\
\hline \multicolumn{9}{|l|}{ Body location } \\
\hline Head & 53 & 40.2 & 20 & 58.8 & $2.13,1.00-4.59$ & .050 & 83 & 45.4 \\
\hline Neck & 25 & 18.9 & 11 & 32.4 & $2.04, .88-4.74$ & .091 & 44 & 24 \\
\hline Arms & 66 & 50.0 & 18 & 52.9 & $1.12, .53-2.39$ & .760 & 94 & 51.4 \\
\hline Hands & 63 & 47.7 & 19 & 55.9 & $1.39, .65-2.96$ & .396 & 94 & 51.4 \\
\hline Anterior trunk & 41 & 31.1 & 17 & 50 & $2.22,1.03-4.78$ & .039 & 68 & 37.2 \\
\hline Posterior trunk & 21 & 15.9 & 10 & 29.4 & $2.20, .92-5.26$ & .072 & 36 & 19.7 \\
\hline Lower limbs & 82 & 62.1 & 22 & 64.7 & $1.12, .51-2.46$ & .781 & 113 & 61.7 \\
\hline Genitals & 5 & 3.8 & 2 & 5.9 & & n.d. & 8 & 4.4 \\
\hline $\begin{array}{l}\text { Low body-image } \\
\text { adjustment }\end{array}$ & 22 & 16.7 & 13 & 38.2 & $3.10,1.35-7.09$ & .006 & 40 & 21.9 \\
\hline \multicolumn{9}{|l|}{ Aetiology } \\
\hline Flame & 88 & 66.7 & 17 & 50 & $2.00, .93-4.30$ & .072 & 113 & 61.7 \\
\hline Scald & 25 & 18.9 & 6 & 17.6 & $1.09, .41-2-.91$ & .863 & 34 & 18.6 \\
\hline Electric & 7 & 5.3 & 3 & 8.8 & $1.73, .42-7.09$ & .429 & 14 & 7.7 \\
\hline Chemical & 7 & 5.3 & 4 & 11.8 & $2.38, .65-8.70$ & .239 & 12 & 6.6 \\
\hline Contact & 5 & 3.8 & 4 & 11.8 & $3.39, .86-13.33$ & .067 & 10 & 5.5 \\
\hline \multicolumn{9}{|l|}{ Place of occurrence } \\
\hline Home & 73 & 55.3 & 14 & 41.2 & $1.77, .82-3.80$ & .141 & 94 & 51.4 \\
\hline Work & 18 & 13.6 & 7 & 20.6 & $1.45, .62-4.33$ & .312 & 28 & 15.4 \\
\hline Street & 14 & 10.6 & 6 & 17.6 & $1.81, .64-5.13$ & .261 & 25 & 13.7 \\
\hline \multirow{2}{*}{$\begin{array}{l}\text { Camping/barbecue } \\
\text { Vehicle }\end{array}$} & 16 & 12.1 & 0 & 0 & & n.d. & 17 & 9.3 \\
\hline & 8 & 6.1 & 6 & 17.6 & $\begin{array}{r}3.32,1.07- \\
10.31\end{array}$ & .030 & 14 & 7.7 \\
\hline Other & 2 & 1.5 & 1 & 2.9 & $1.97, .17-22.22$ & .578 & 5 & 2.6 \\
\hline \multicolumn{9}{|c|}{ Circumstance of occurrence } \\
\hline Occupational & 16 & 12.1 & 8 & 23.5 & $2.23, .86-5.78$ & .092 & 27 & 14.8 \\
\hline \multirow{2}{*}{$\begin{array}{l}\text { Suicide attempt } \\
\text { Motor Vehicle Accident }\end{array}$} & 2 & 1.5 & 2 & 5.9 & & n.d. & 11 & 6 \\
\hline & 6 & 4.5 & 6 & 17.6 & $\begin{array}{r}4.50,1.35- \\
14.93\end{array}$ & .009 & 12 & 6.6 \\
\hline Aggression & 8 & 6.1 & 1 & 2.9 & & n.d. & 4 & 2.2 \\
\hline Other accidents & 100 & 75.8 & 17 & 50 & $.32, .15-.70$ & .003 & 129 & 70.5 \\
\hline
\end{tabular}




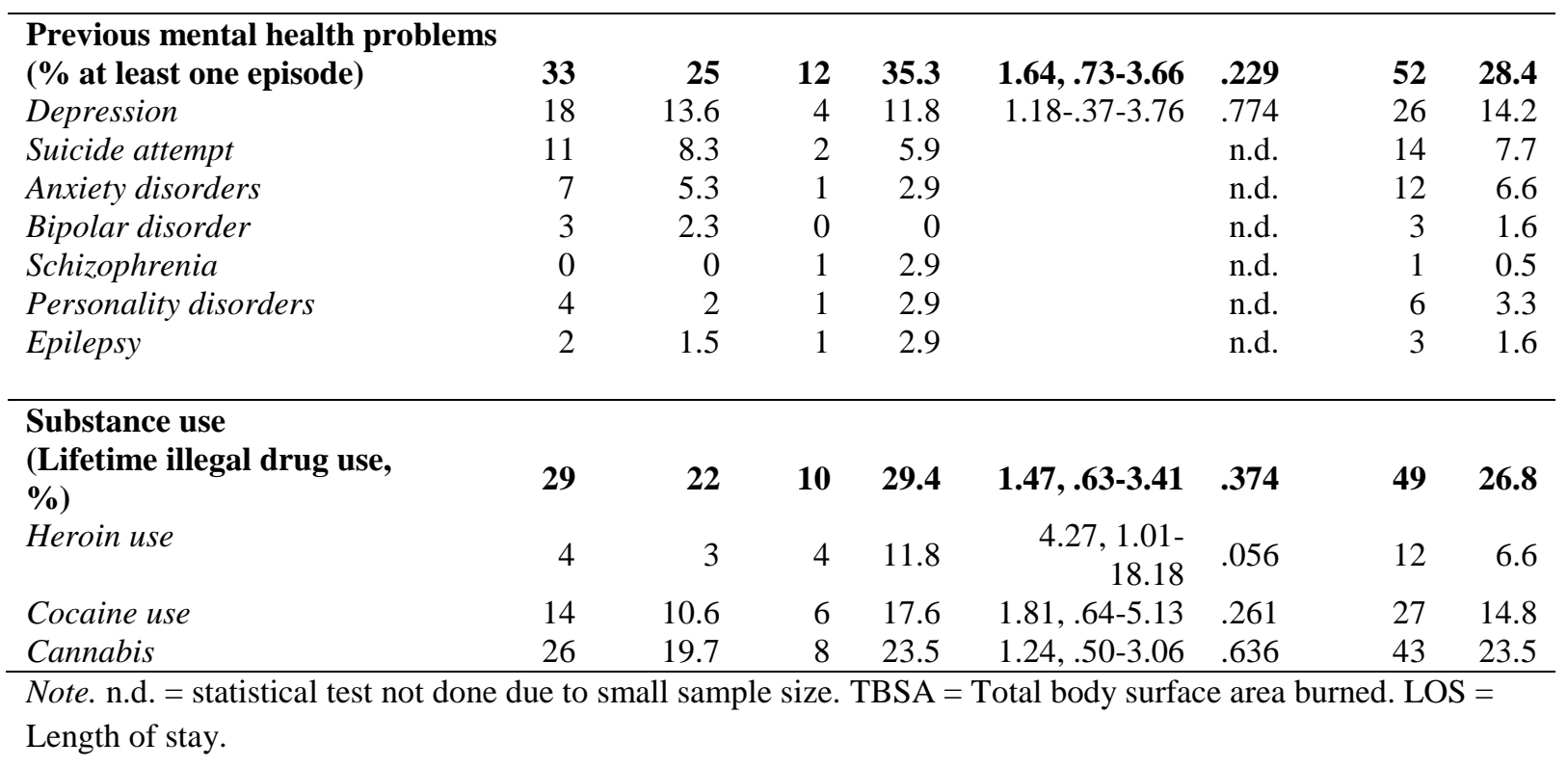

\section{Reliability of instruments and efficiency of the DTS.}

All outcome reliabilities ranged between $\alpha=0.5$ and $\alpha=0.9$. In this study, the highest efficiency for the DTS versus the diagnosis carried with the MINI at six months, made using a ROC curve, showed an optimal cut-off threshold for the DTS on a score of 28 as it was the limit of both optimal sensibility (1) and specificity (0.939). The area under the curve was found to be $0.987 \pm 0.007(p<0.0001)$, see figure 2 .

Figure 2. ROC curve illustrating the accuracy of DTS predicting PTSD as measured by the MINI: 


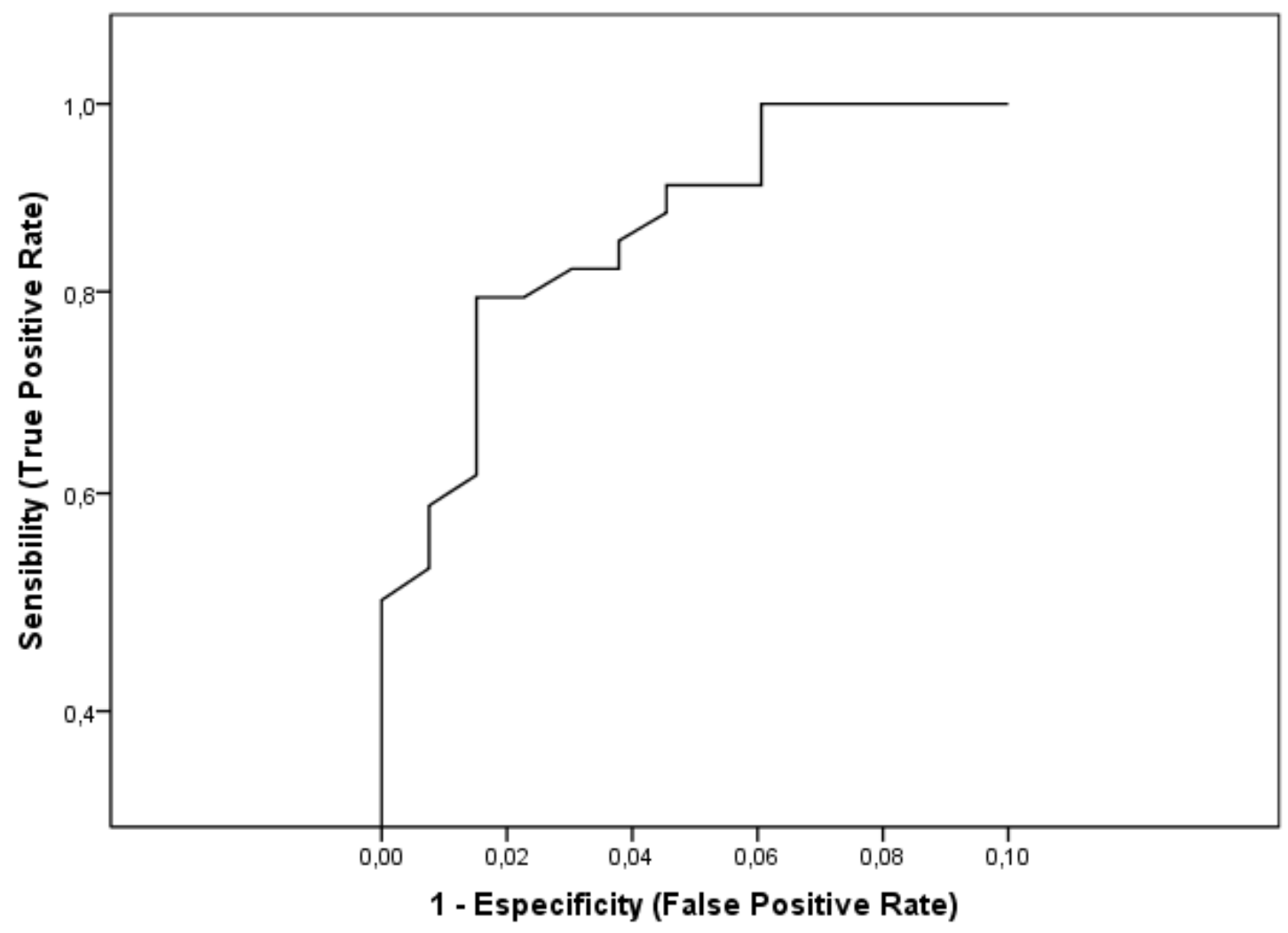

DTS: Davidson Trauma Scale

MINI: Mini International Neuropsychiatric Interview

\section{Progression of psychopathology scores.}

As can be seen in figure 3, box plots of psychopathology scores showed a generalized decreasing tendency across assessments. Depression (BDI) departed from a slightly positive skewed distribution (0.9) going towards a complete asymmetric distribution (1.7), while anxiety (STAI) distributions tended to remain symmetric (0.7-1.1). Posttraumatic symptoms were yet positive skewed at baseline (avoidance $=1.8$, intrusion=2.1, hyperarousal=3) and tended to a highly positive skewed distribution at six months, although hyperarousal remained within the same values (avoidance=3.5, intrusion=3.1, hyperarousal=2.9).

Figure 3. Distribution of mental health scoring across the assessments. 
BDI: Beck Depression Inventory, STAI: State Trait Anxiety Inventory, IES : Impact of Event Scale

\subsection{Differential features of patients with and without PTSD}

At 6 months, 34 patients presented PTSD (20.5\% of 166 patients reached at 6 months), 22 a depressive disorder (13.3\%) and 9 generalized anxiety $(5.4 \%)$ as measured with the MINI Neuropsychiatric Interview. Considering sociodemographic features (table 1), low economic income was significantly greater in people with PTSD (OR=2.88, 95\% CI=1.24-6.71, $p<.01)$. Although the percentage of females in the PTSD subsample was greater, there were no more statistical significant differences between the two groups.

Regarding clinical features (table 2), there were statistically significant differences between the two subsamples on injury characteristics such as third degree burns $\left(\chi^{2}=3.98\right.$, 
$p=0.046)$. Peritraumatic symptoms, including dissociative amnesia $(t=-2.47, \mathrm{p}=0.018)$, life threat perception $(\mathrm{OR}=3.21,95 \% \mathrm{CI}=1.46-7.04, p=.003)$ and getting emotionally paralyzed at the burn injury episode $(\mathrm{OR}=2.64,95 \% \mathrm{CI}=1.08-6.42, p=.028)$ were higher in patients diagnosed of PTSD. In relation to body location, head $(\mathrm{OR}=2.13,95 \% \mathrm{CI}=1.00-4.59, p<.050)$ and anterior trunk $(\mathrm{OR}=2.22,95 \% \mathrm{CI}=1.03-4.78, p=.039)$ were also statistically related to PTSD. Traumatic burn circumstances like motor vehicle accident (MVA; OR=3.32, 95\% $\mathrm{CI}=1.07-10.31, p=.009)$, other accidents $(\mathrm{OR}=.32,95 \% \mathrm{CI}=.15-.70, p=.003)$ were also significantly related to posttraumatic stress. The only place of injury occurrence which resulted in a statistical significant difference was a motor vehicle $(\mathrm{OR}=3.32,95 \% \mathrm{CI}=1.07$ 10.31, $p=.033)$. A poor body-image adjustment was also related to PTSD (OR=3.10, 95\% $\mathrm{CI}=1.35-7.09, p=.006)$. Only four patients were burned as the result of a suicide attempt. Although no statistical tests could be carried due to the small size of this subsample, the occurrence of PTSD was $50 \%$, being suicidal patients $6 \%$ of the total group of patients with PTSD. No more variables showed statistically significant differences when comparing patients diagnosed with PTSD at 6 months with the rest.

Psychopathology progression within these groups of patients was found to be statistically different (see figure 4). Specifically, linear and Quadratic progressions showed statistically significant differences $(F=8-12, \quad p>.0001$ in all cases $)$ when comparing trajectories of patients with and without PTSD and those not reached at six months (without MINI assessment). In this regard, as reflected in figure 4, patients diagnosed with PTSD at 6 months had a similar initial progression but anxiety, depression and hyperarousal increased after the 30 days, and avoidance after the 90 days assessment points. DTS scores differences between participants with and without a diagnosis of PTSD at six months increased over time (30.7 vs. 14.3 at 30 days, 40.4 vs. 9.9 at 90 days, and 50.9 vs. 7.6 at 180 days, all p<.0001). 
Cite as: Fidel-Kinori, S. G., Eiroa-Orosa, F. J., Giannoni-Pastor, A., Tasqué-Cebrián, R., Arguello, J. M., \& Casas, M. (2016). The Fenix II study: A longitudinal study of psychopathology among burn patients. Burns, 42(6), 1201-1211. http://doi.org/10.1016/j.burns.2016.01.026

Figure 4. Comparison of psychological symptoms evolution from participants with and without PTSD and participants with 6 months assessment not reached.

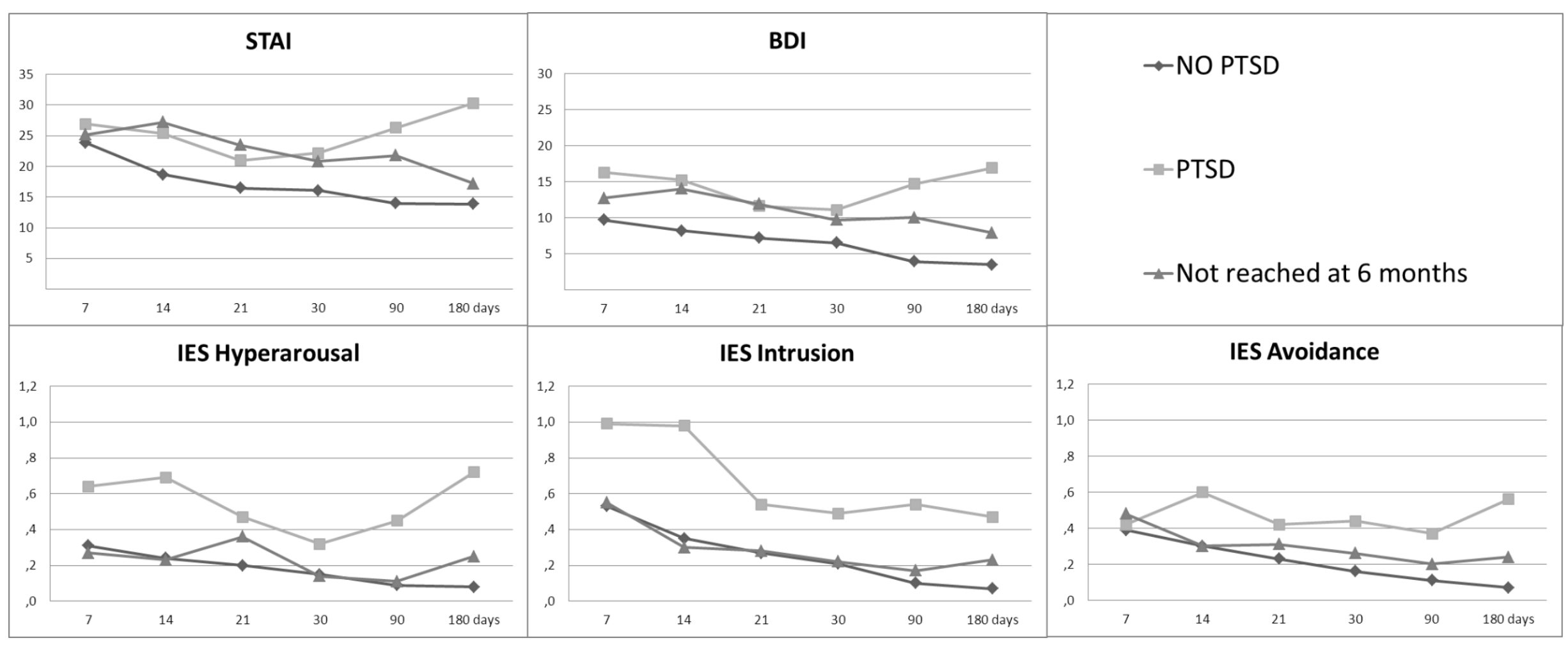

BDI: Beck Depression Inventory, STAI: State Trait Anxiety Inventory, IES : Impact of Event Scale 
The results of the discriminant analysis can be seen in table 3 . The variables with higher standardized canonical coefficients were, in this order (only coefficients over 0.3): MVA as injury mechanism (0.670), low economic income (0.379), low body-image adjustment (0.346) and anterior trunk as body location (0.321). Sensitivity was moderately high $(73.5 \%)$, being specificity higher (81.4\%). Global correct classification was $79.8 \%$.

Table 3. Standardized canonical discriminant function coefficients and classification results of the discriminant analysis.

\begin{tabular}{ll}
\hline \hline Predictors of PTSD at 6 months $(\mathbf{N = 1 6 3})$ & \\
\hline MVA & 0.670 \\
Low economic income & 0.379 \\
Low body-image adjustment & 0.346 \\
Anterior trunk location & 0.321 \\
Life threat perception & 0.289 \\
Head injury location & 0.223 \\
Casual accidents & 0.181 \\
Third-degree burns & 0.163 \\
Get paralyzed at the injury event & 0.158 \\
Peritraumatic dissociative amnesia & 0.157 \\
Vehicle as a place of occurrence & 0.113 \\
Peritraumatic sensory numbness & 0.047
\end{tabular}

PTSD criteria model classification at 6 months

\section{Predicted}

PTSD No PTSD

$\begin{array}{lllll}\text { Original } & \mathrm{N} & \% & \mathrm{~N} & \% \\ \text { PTSD } & 25 & 73.5 & 9 & 26.5 \\ \text { No PTSD } & 24 & 18.6 & 105 & 81.4\end{array}$

Global $79.8 \%$ of original grouped cases correctly classified.

Note. MVA = Motor Vehicle Accident. PTSD= Post-Traumatic Stress Disorder. 


\section{Discussion}

This study was the first to address the progression of posttraumatic symptomatology of a large sample of burn patients in a Spanish population. Trying to add relevant information to other international studies, we monitored carefully the first six months of progression in order to identify clinical and psychosocial predictors of PTSD and patterns of early progression.

As seen in the results section, included and excluded patients were comparable with regard to age, gender and TBSA. The statistically significant difference in the variances of age could be explained by the fact that many old people are admitted for prevention and young people heal faster. For these reasons, these groups were less likely to be included in the study. The same was found for the TBSA variable. This is probably due to a higher proportion of excluded patients having less than $5 \%$ or a higher TBSA. The former group of patients could not be followed up due to their short admission period, and the latter were unreachable due to the severity of their injuries. These circumstances could be compared with the results of Holavanahalli et al. [38]. This research group also lost to follow-up younger patients. However, their sample decreased across assessments, in contrast with our study in which we tried to recover as many patients as possible always considering their delicate health situation.

The clinical and sociodemographic features of our sample were similar to other studies, with the percentage of females ranging from 21 to $27 \%$, the mean age ranging 37-45 years, the average TBSA burned ranging 14-22\%, and the mean LOS range being 20-24 days [18,39-41].

As we could see in the figures representing symptomatology progression, psychological symptoms showed a generalized decreasing tendency across the 6 months 
period after burn. Intrusion as measured by the IES-R was present in most patients at baseline, but as assessments were carried, only a minority of patients continued to experience clinically significant symptomatology. Avoidance symptoms were yet low during acute care. The same happened with hyperarousal symptoms. Nevertheless, they showed an increase at 6 months assessment when patients were trying to recover daily life. Depressive symptoms were low at baseline and decreased over time. This was in contrast with anxiety symptoms, which remained at a high level across the whole study period. Among patients diagnosed with PTSD at 6 months, anxiety, depression and hyperarousal increased after the 30 days assessment, and avoidance after the 90 days assessment, confirming the importance of follow-up availability once patients have been discharged from surgical services $[42,43]$.

An optimal cut-off rating for the DTS was found to be 28 at six months. This is in line with former studies [32] demonstrating that lower cut-off points are equally efficient than the original recommended point, although these authors warned that this may be highly dependent on the comparison group used for analyses. In the case of burn patients, we think it is better to prioritize sensibility as we think that PTSD must be carefully screened and followed up in order to prevent its possible consequences.

In relation to sociodemographic features, comparisons between groups with and without PTSD showed that low economic income (continued difficulties accessing housing, education and/or employment), but social support was not related to PTSD at 6 months. Low income has been related to higher levels of PTSD in different groups of people experiencing trauma [44]. This is probably because people with low economic income levels tend to have less social support and fewer resources to deal with the recovery process. Several studies have explored the relationship of different socioeconomic variables with PTSD among burn patients, including social functioning 
[15], social support [21], occupational functioning [45], and leisure arrangements [35]. Although differences in the concept, the type of population, and the different measures and time of measurement used make it difficult to draw conclusions, it is possible that regardless of the perceived level of social support, these patients, either by their prior or acquired inability to adapt to the social environment, have a greater vulnerability to mental distress after a burn injury.

Although the proportion of females in the PTSD group was greater, no statistical significant differences were found between the two subsamples in relation to gender. This has happened in some other studies [46], although on the contrary, other studies with burn patients found that female gender was related to PTSD $[47,48]$. One possible explanation could be the use of the MINI as a diagnostic tool. This is in line with general population studies where significant gender differences in the prevalence of PTSD were found using ICD-10 criteria, but such differences were not found using DSM-IV criteria [49].

With regard to clinical characteristics, there were statistically significant differences between the two subsamples on some injury variables such as third degree of burns. This variable did not use to appear as an impact variable in other studies, such as TBSA or LOS did $[10,39,50]$. On the other hand, as found in similar studies, TBSA and LOS only showed a statistical tendency to be associated with PTSD, [51,52]. In addition, peritraumatic symptoms such as dissociative amnesia and life threat perception had previously found to be related with PTSD symptoms [18,39]. Finally, being emotionally paralyzed during the event appears as a new variable related with stress. It can be contextualized within the frighten reactions happening during a traumatic experience. 
In relation to body location, head and anterior trunk were also statistically associated with PTSD. These variables are closely related with poor body-image, which also appeared as a bivariate predictor of PTSD in this study, as well as in previous research [13]. The visibility of the injury and risk of disfigurement, combined with female gender, had shown significant association with stress symptoms in burn patients $[53,54]$. However, as commented above, in this study gender had no direct statistical significant association with PTSD. Additionally, in contrast with previous literature, the report of previous mental health and substance use problems did not show a statistically significant relation with the development of PTSD at six months (although the odds were $50 \%$ higher). We hypothesize that this may be due to the different characteristics of the groups that make up our sample. This includes people in danger of social exclusion and already suffering serious mental health problems and illegal drug use. In both cases these groups made up almost one third of the sample, well above rates registered in other burn samples [55,12]. In these cases, the characteristics of the accident that caused the burn may be related to high risk activities such as copper theft from street lights or the drowsiness caused by the consumption of benzodiazepines. The lack of statistical significant relations of previous psychiatric diagnoses with PTSD in a heterogeneous population like this, should not imply carelessness, in fact, these populations deserve a detailed study of their characteristics and risk of developing psychological sequels.

Traumatic burn circumstances like motor vehicle (MVA) and other (a category which included activities which are supposed to imply low risk such as scald or steam burns) accidents, as well as a motor vehicle as a place of injury occurrence, were also statistically different between groups. Having a traffic accident is a traumatic experience that comes with a strong visual and physical impact, in addition to an inevitable 
perception of vulnerability. Studies with MVA victims had found high prevalence of PTSD, with an average of $39 \%$ of the sample receiving a diagnosis, and degrees of physical injury as powerful predictors [56,57]. These findings should explain why patients burned in a MVA were one of the most vulnerable individuals to develop stress symptoms in this study.

After the discriminant analysis, the four main variables were, in order of weight: MVA as injury mechanism, low economic income, low body-image adjustment and anterior trunk as body location of burn. Motor vehicle as a place of occurrence also had a considerable weight but less than MVA as a mechanism of burn injury. One possible explanation for that difference could be that accidents not always happened inside a vehicle, as MVAs in our study also involved pedestrians who usually are the most vulnerable victims.

Limitations of the study should also been addressed. In relation to methodological problems, the administration of the instruments at once on each followup may have had some influence on the relationship between different types of psychopathology, and for example the concurrent validity of DTS and the diagnosis of PTSD done with the MINI may be increased since certain questions are virtually identical. We also had a high percentage of dropouts, although it is similar to those found by other studies in this area [4]. Body image adaptation could not be measured with a validated standardized measure as we had to register body image adaptation in a way which warranted compatibility with the Hospital's daily practice, trying not to overburden acute patients with even more questionnaires. However, our goal was not to create a reliable score, but screen all persons likely to have been affected by an image change. Finally, ethnic minorities could not be separately analyzed as there was no enough sample. Nevertheless, we have addressed many of other limitations identified in 
the literature, such as the use of non-standardized measures, or the use of retrospective chart reviews. Also, in our sample, PTSD was evenly distributed among genders, making possible to carry analyses without further stratification.

Factors involved in susceptibility to post-traumatic symptoms varies across studies. Future research should continue the evaluation of the relationship between predictors and psychological symptomatology over time. Considering that mental health symptoms in burn patients may persist for years after the injury, research may address whether these predictors remain influential or rather other factors develop new influences in the long term. Specifically, it would be advisable to explore in greater depth the group of patients suffering burns in the context of a MVA, as circumstances surrounding these accidents usually cause greater psychological impact.

In conclusion, research and clinical practice should focus in all variables related to the impact of traumatic events regardless of their biological, psychological or social nature. Although the development of psychopathological symptoms after a burn injury could appear hard to prevent, identifying in advance risk factors and being attentive to the progression of symptoms may help to better understand these problems, providing the best interventions for the most vulnerable populations.

\section{Acknowledgements}

We would like to thank patients who offered their time and confidence to participate in this study, and to all the staff of the Plastic Surgery and Burns Department of the Vall d'Hebron University Hospital for facilitating access to them. This work was supported by the Research Institute of the University Hospital Vall d'Hebron (VHIR) in Barcelona and with a grant of the Department of Health, Government of Catalonia, Spain. 


\section{References}

[1] Peck MD. Epidemiology of burns throughout the world. Part I: Distribution and risk factors. Burns 2011;37:1087-100. doi:10.1016/j.burns.2011.06.005.

[2] Brusselaers N, Hoste EAJ, Monstrey S, Colpaert KE, De Waele JJ, Vandewoude $\mathrm{KH}$, et al. Outcome and changes over time in survival following severe burns from 1985 to 2004. Intensive Care Med 2005;31:1648-53. doi:10.1007/s00134005-2819-6.

[3] American Burn Association. National Burn Repository 2014. http://www.ameriburn.org/2014NBRAnnualReport.pdf.

[4] McKibben JBA, Ekselius L, Girasek DC, Gould NF, Holzer C, Rosenberg M, et al. Epidemiology of burn injuries II: psychiatric and behavioural perspectives. Int Rev Psychiatry 2009;21:512-21. doi:10.3109/09540260903343794.

[5] Blakeney PE, Rosenberg L, Rosenberg M, Faber AW. Psychosocial care of persons with severe burns. Burns 2008;34:433-40. doi:10.1016/j.burns.2007.08.008.

[6] Van Loey NEE, Van Son MJM. Psychopathology and Psychological Problems in Patients with Burn Scars. Am J Clin Dermatol 2003;4:245-72. doi:10.2165/00128071-200304040-00004.

[7] Ter Smitten MH, de Graaf R, Van Loey NE. Prevalence and co-morbidity of psychiatric disorders 1-4 years after burn. Burns 2011;37:753-61. doi:10.1016/j.burns.2010.12.018.

[8] Wisely JA, Wilson E, Duncan RT, Tarrier N. Pre-existing psychiatric disorders, psychological reactions to stress and the recovery of burn survivors. Burns 2010;36:183-91. doi:DOI: 10.1016/j.burns.2009.08.008.

[9] Wisely JA, Hoyle E, Tarrier N, Edwards J. Where to start? Attempting to meet the psychological needs of burned patients. Burns 2007;33:736-46. doi:10.1016/j.burns.2006.10.379.

[10] Patterson DR, Carrigan L, Questad KA, Robinson R. Post-traumatic stress disorder in hospitalized patients with burn injuries. J Burn Care Rehabil 1990;11:181-4.

[11] Baur KM., Hardy PE., Dorsten B. Posttraumatic Stress Disorder in Burn Populations: A Critical Review of the Literature. J Burn Care Rehabil 1998;19.

[12] Giannoni-Pastor A, Eiroa-Orosa FJ, Fidel Kinori SG, Arguello JM, Casas M. Prevalence and Predictors of Posttraumatic Stress Symptomatology Among Burn Survivors: A Systematic Review and Meta-Analysis. J Burn Care Res 2016;37:e79-89. doi:10.1097/BCR.0000000000000226.

[13] Madianos MG, Papaghelis M, Ioannovich J, Dafni R. Psychiatric Disorders in Burn Patients: A Follow-Up Study. Psychother Psychosom 2001;70:30-7. doi:10.1159/000056222.

[14] Lu M-K, Lin Y-S, Chou P, Tung T-H. Post-traumatic stress disorder after severe burn in southern Taiwan. Burns 2007;33:649-52. doi:DOI: 10.1016/j.burns.2006.09.004.

[15] El hamaoui Y, Yaalaoui S, Chihabeddine K, Boukind E, Moussaoui D. Posttraumatic stress disorder in burned patients. Burns 2002;28:647-50.

[16] Mora AG, Ritenour AE, Wade CE, Holcomb JB, Blackbourne LH, Gaylord KM. Posttraumatic Stress Disorder in Combat Casualties With Burns Sustaining Primary Blast and Concussive Injuries. J Trauma Inj Infect Crit Care 2009;66:S178-85. doi:10.1097/TA.0b013e31819ce2d6.

[17] Yu BH, Dimsdale JE. Posttraumatic stress disorder in patients with burn injuries. J Burn Care Rehabil 1999;20:426-33; discussion 422-5. 
[18] Willebrand M, Andersson G, Ekselius L. Prediction of Psychological Health After an Accidental Burn. J Trauma Inj Infect Crit Care 2004;57:367-74. doi:10.1097/01.TA.0000078697.69530.0E.

[19] Andrews RM, Browne AL, Drummond PD, Wood FM. The impact of personality and coping on the development of depressive symptoms in adult burns survivors. Burns 2010;36:29-37. doi:10.1016/j.burns.2009.06.202.

[20] Bosmans MWG, Hofland HW, De Jong AE, Van Loey NE. Coping with burns: the role of coping self-efficacy in the recovery from traumatic stress following burn injuries. J Behav Med 2015;38:642-51. doi:10.1007/s10865-015-9638-1.

[21] Perry S, Difede J, Musngi G, Frances AJ, Jacobsberg L. Predictors of posttraumatic stress disorder after burn injury. Am J Psychiatry 1992;149:931-5.

[22] World Health Organization. Disease and injury regional estimates. Heal Stat Heal Inf Syst 2008. http://www.who.int/healthinfo/global_burden_disease/estimates_regional/en/inde x.html.

[23] Barret J., Gomez P, Solano I, Gonzalez-Dorrego M, Crisol F. Epidemiology and mortality of adult burns in Catalonia. Burns 1999;25:325-9. doi:10.1016/S03054179(98)00190-9.

[24] Weathers FW, Ruscio AM, Keane TM. Psychometric properties of nine scoring rules for the Clinician-Administered Posttraumatic Stress Disorder Scale. Psychol Assess 1999;11:124-33. doi:10.1037/1040-3590.11.2.124.

[25] Folstein MF, Folstein SE, Mc Hugh PR. Mini-Mental State: A practical method for grading the cognitive state of patients for the clinician. J Psychiatr Res 1975;12:189-98.

[26] Spielberger CD, Gorsuch RL, Lushene R, Vagg PR, Jacobs GA. Manual for the State-Trait Anxiety Inventory. Palo Alto: Consulting Psychologists' Press; 1983.

[27] Beck AT, Steer RA, Brown GK. Manual for the Beck depression inventory-II. 1996.

[28] Weiss D, Marmar C. The Impact of Event Scale-Revised. In: Wilson J, Keane T, editors. Assess. Psychol. trauma PTSD, New York: Guilford Press; 1997, p. 399-411.

[29] Sveen J, Orwelius L, Gerdin B, Huss F, Sjöberg F, Willebrand M. Psychometric Properties of the Impact of Event Scale-Revised in Patients One Year After Burn Injury. J Burn Care Res 2010;31:310-8 10.1097/BCR.0b013e3181d0f523.

[30] Davidson JRT, Book SW, Colket JT, Tupler LA, Roth S, David D, et al. Assessment of a new self-rating scale for post-traumatic stress disorder. Psychol Med 1997;27:153-60.

[31] Fauerbach JA, Lawrence JW, Munster AM, Palombo DA, Richter D. Prolonged adjustment difficulties among those with acute posttrauma distress following burn injury. J Behav Med 1999;22:359-78.

[32] McDonald SD, Beckham JC, Morey RA, Calhoun PS. The validity and diagnostic efficiency of the Davidson Trauma Scale in military veterans who have served since September 11th, 2001. J Anxiety Disord 2009;23:247-55. doi:10.1016/j.janxdis.2008.07.007.

[33] Lecrubier Y, Sheehan D, Weiller E, Amorim P, Bonora I, Harnett Sheehan K, et al. The Mini International Neuropsychiatric Interview (MINI). A short diagnostic structured interview: reliability and validity according to the CIDI. Eur Psychiatry 1997;12:224-31. doi:10.1016/S0924-9338(97)83296-8.

[34] Sheehan D, Lecrubier Y, Harnett Sheehan K, Janavs J, Weiller E, Keskiner A, et al. The validity of the Mini International Neuropsychiatric Interview (MINI) 
according to the SCID-P and its reliability. Eur Psychiatry 1997;12:232-41. doi:10.1016/S0924-9338(97)83297-X.

[35] Lu M-K, Lin Y-S, Chou P, Tung T-H. Post-traumatic stress disorder after severe burn in southern Taiwan. Burns 2007;33:649-52. doi:10.1016/j.burns.2006.09.004.

[36] Falder S, Browne A, Edgar D, Staples E, Fong J, Rea S, et al. Core outcomes for adult burn survivors: a clinical overview. Burns 2009;35:618-41. doi:10.1016/j.burns.2008.09.002.

[37] McKibben JBA, Bresnick MG, Wiechman Askay SA, Fauerbach JA. Acute stress disorder and posttraumatic stress disorder: a prospective study of prevalence, course, and predictors in a sample with major burn injuries. J Burn Care Res 2008;29:22-35. doi:10.1097/BCR.0b013e31815f59c4.

[38] Holavanahalli RK, Lezotte DC, Hayes MP, Minhajuddin A, Fauerbach JA, Engrav LH, et al. Profile of patients lost to follow-up in the Burn Injury Rehabilitation Model Systems' longitudinal database. J Burn Care Res 2006;27:703-12. doi:10.1097/01.BCR.0000238085.87863.81.

[39] Van Loey NEE, Maas CJM, Faber a W, Taal L a. Predictors of chronic posttraumatic stress symptoms following burn injury: results of a longitudinal study. J Trauma Stress 2003;16:361-9. doi:10.1023/A:1024465902416.

[40] Fauerbach JA, McKibben JBA, Bienvenu OJ, Magyar-Russell G, Smith MT, Holavanahalli R, et al. Psychological Distress After Major Burn Injury. Psychosom Med 2007;69:473-82. doi:10.1097/psy.0b013e31806bf393.

[41] Wallis H, Renneberg B, Ripper S, Germann G, Wind G, Jester A. Emotional distress and psychosocial resources in patients recovering from severe burn injury. J Burn Care Res 2006;27:734-41. doi:10.1097/01.BCR.0000238094.33426.0D.

[42] Wallace LM, Lees J. A psychological follow-up study of adult patients discharged from a British burn unit. Burns 1988;14:39-45. doi:10.1016/S03054179(98)90040-7.

[43] Overton TL, Shafi S, Gandhi RR. Local access to care programs increase trauma patient follow-up compliance. Am J Surg 2014;208:476-9. doi:10.1016/j.amjsurg.2013.11.008.

[44] Widows MR, Jacobsen PB, Fields KK. Relation of psychological vulnerability factors to posttraumatic stress disorder symptomatology in bone marrow transplant recipients. Psychosom Med 2000;62:873-82.

[45] Palmu R, Partonen T, Suominen K, Vuola J, Isometsä E. Functioning, Disability, and Social Adaptation 6 Months After Burn Injury. J Burn Care Res 2015:1. doi:10.1097/BCR.0000000000000258.

[46] Meyer WJ, Blakeney P, Thomas CR, Russell W, Robert RS, Holzer CE. Prevalence of major psychiatric illness in young adults who were burned as children. Psychosom 2007;69:377-82. doi:10.1097/PSY.0b013e3180600a2e.

[47] Klinge K, Chamberlain DJ, Redden M, King L. Psychological adjustments made by postburn injury patients: an integrative literature review. J Adv Nurs 2009;65:2274-92. doi:10.1111/j.1365-2648.2009.05138.x.

[48] Michaels AJ, Michaels CE, Zimmerman MA, Smith JS, Moon CH, Peterson C. Posttraumatic Stress Disorder in Injured Adults: Etiology by Path Analysis. J Trauma Inj Infect Crit Care 1999;47:867. doi:10.1097/00005373-19991100000009.

[49] Peters L, Issakidis C, Slade T, Andrews G. Gender differences in the prevalence 
of DSM-IV and ICD-10 PTSD. Psychol Med 2006;36:81-9. doi:10.1017/S003329170500591X.

[50] Ehde DM, Patterson DR, Wiechman SA, Wilson LG. Post-traumatic stress symptoms and distress 1 year after burn injury. J Burn Care Rehabil 2000;21:105-11.

[51] Palmu R, Suominen K, Vuola J, Isometsä E. Mental disorders after burn injury: a prospective study. Burns 2011;37:601-9. doi:10.1016/j.burns.2010.06.007.

[52] Tedstone JE, Tarrier N. An investigation of the prevalence of psychological morbidity in burn-injured patients. Burns 1997;23:550-4.

[53] Fukunishi I. Relationship of Cosmetic Disfigurement to the Severity of Posttraumatic Stress Disorder in Burn Injury or Digital Amputation. Psychother Psychosom 1999;68:82-6. doi:10.1159/000012317.

[54] Van Loey NEE, Van Son MJM. Psychopathology and psychological problems in patients with burn scars: epidemiology and management. Am J Clin Dermatol 2003;4:245-72.

[55] Eiroa-Orosa FJ, Giannoni-Pastor A, Fidel-Kinori SG, José María A-A. Substance use and misuse in burn patients: testing the classical hypotheses of the interaction between posttraumatic symptomatology and substance use. J Addict Dis 2016. doi:10.1080/10550887.2015.1127717.

[56] Blanchard EB, Hickling EJ, Taylor AE, Loos WR, Forneris CA, Jaccard J. Who develops PTSD from motor vehicle accidents? Behav Res Ther 1996;34:1-10.

[57] Maes M, Mylle J, Delmeire L, Altamura C. Psychiatric morbidity and comorbidity following accidental man-made traumatic events: incidence and risk factors. Eur Arch Psychiatry Clin Neurosci 2000;250:156-62. 